\section{Vivir en el encierro: interacciones en un Centro de Tratamiento para Adolescentes}

Living in confinement: interactions in an Adolescent Treatment Center
Christian Fernández Huerta, Anuar Figueroa Estrada

\section{RESUMEN}

Este artículo abordó el significado que los jóvenes les otorgan a las interacciones sociales dentro del Centro de Tratamiento para Adolescentes (CTA) y al proceso de reinserción social proporcionado por el Estado y que han ingresado a dicho centro. Debido a la falta de permiso para grabar audio y/o video dentro de las instalaciones del CTA, se optó por talleres donde se abordaron distintos temas relacionados con la violencia, la familia, expectativas sobre su futuro, entre otros; con la finalidad de registrar a través de dibujos, cuestionarios y relatos, sus vidas antes del delito y sus estancias dentro del CTA. En el camino a la reinserción social, estos jóvenes cargan un estigma que no disminuye y conforme se acerca el fin del tratamiento crece la incertidumbre de volver al exterior, pues la habituación a las normas institucionales del encierro implica también un trabajo de readaptación a la vida en libertad.

Palabras clave: Juventud; Encierro; Interacciones; Reinserción social

\section{ABSTRACT}

This paper aims to understand the meaning that young people who have entered the Adolescent Treatment Center (CTA in Spanish) give to social interactions within the institution and to the processes of social reintegration provided by the State. Due to the lack of permission to record audio and / or video within the facilities of the CTA, workshops were created, where different topics related to violence, family, expectations about their future, among others, were addressed, in order to register -through their own handwriting-, drawings, questionnaires and stories or their lives before the crime and about their stay inside the CTA. On the way to social reintegration, these young people carry a stigma that does not diminish and as the end of treatment approaches, the uncertainty of returning to the outside grows more, because the habituation to the institutional norms of confinement also implies a work of rehabilitation to life in freedom.

Keywords: Youth; Confinement; Interactions; Social reintegration
INFORMACIÓN:

https://doi.org/10.46652/pacha.v2i6.69 ISSN 2697-3677

Vol. 2, No. 6, 2021. e21069

Quito, Ecuador

Enviado: 06 marzo 2021

Aceptado: 15 agosto 2021

Publicado: 26 octubre 2021

Sección General | Peer Reviewed

Publicación continua
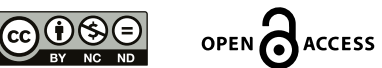

AUTORES:

Christian Fernández Huerta Universidad Autónoma de Baja California - México

christian@uabc.edu.mx

Anuar Figueroa Estrada

Instituto de Psiquiatría del Estado de Baja California - México

anuar.figueroa@uabc.edu.mx

\section{CONFLICTO DE INTERESES}

Los autores declaran que no existe conflicto de interés posible.

FINANCIAMIENTO

No existió asistencia financiera de partes externas al presente artículo. NOTA

El articulo es parte de un proyecto de varios años con jóvenes internos en el Centro de Ejecución de Medidas para Adolescentes de Baja California.

ENTIDAD EDITORA 


\section{Introducción}

Estudiar a los jóvenes infractores, puede remitirnos al tema de drogas y violencia. Los contextos sociales y familiares de menores infractores se relacionan con la temática de las drogas: vulnerabilidad, precariedad, conflictos familiares, violencia y/o abuso, disponibilidad de drogas, entre otras (SISVEA, 2013; Vilariño et al., 2013). Estos contextos exponen a la juventud a situaciones de riesgo de consumo de sustancias adictivas y a comportamientos antisociales o delictivos. El Estado mexicano asume el deber de corregir y reformar a través de la creación de instituciones encaminadas a la reinserción social. Estos lugares han cumplido a través de la historia una función particular, aunque ha llevado distintos nombres como: correccional, centros de reeducación, de reinserción o de tratamiento -la finalidad última es-, que jóvenes infractores sean encausados nuevamente a la norma (Bailón, 2012).

El inicio de las actividades delictivas generalmente ocurre en la juventud y particularmente son los hombres jóvenes quienes son más susceptibles a incurrir en actividades como el comercio informal, el narcotráfico, robos a pequeña escala y crimen organizado (Connell, 2003). También es en hombres jóvenes donde encontramos mayor prevalencia de consumo de alcohol, tabaco y drogas ilegales. Aunque es notable el aumento del consumo de drogas en mujeres, principalmente en las de menor edad, así como su participación en delitos y crimen organizado, en dichas prácticas predomina la presencia de hombres (Medina-Mora et al., 2012; Villatoro-Velázquez et al., 2015; Acero González et al., 2007). Esto, según Núñez Noriega (2005), responde a que nuestra sociedad invisibiliza las construcciones de género como factor que interviene en la conducta infractora.

En el periodo del trabajo de campo de este proyecto de investigación, en Baja California, aumentaron los delitos un $4.7 \%$ en 2017 con respecto al año anterior, y esta tendencia sigue en alza. La comisión del delito especifica los siguientes rubros: robo con y sin violencia, lesiones, homicidios dolosos y culposos, delitos patrimoniales, secuestros, violación y otros. Estos datos abarcan los 5 municipios del estado de Baja California, así como adolescentes infractores y adultos (SSPE, 2018). En el $4 \%$ de los delitos cometidos están involucrados menores. ¿Qué sucede cuando estos menores que cometen delitos ingresan a las instituciones que buscan corregirlos a través de medidas socio educativas especiales? ¿Cómo interpretan y asimilan estos tratamientos o medidas dedicadas a reeducar, reformar y encausar un comportamiento "anormal" o "desviado"? Estas preguntas nos permiten explorar y describir algunos de los sentidos y de las expectativas que estos jóvenes construyen sobre su futuro dentro y fuera de la institución diseñada para su reinserción social.

Para ayudar a dar respuestas a estas interrogantes, el documento busca articular los discursos de los jóvenes y sus vivencias en el encierro con los autores de los primeros apartados, privilegiando la experiencia de los jóvenes, su sentir y decir, sobre el análisis desde lo teórico.

\section{Metodología}

Esta investigación cualitativa de corte transversal tiene como objetivo comprender el significado que los jóvenes ingresados al Centro de Tratamiento para Adolescentes (CTA) les dan a las interacciones sociales en la vida cotidiana y a los procesos de reinserción social proporcionados por el Estado. Dichos significados se expresan a través de la vida cotidiana, por lo que se seleccionaron cuatro jóvenes hombres cuya permanencia en el CTA fuera de más de un año: esto permitió observar y 
registrar aspectos de la cotidianeidad de estos jóvenes habituados al lugar. Lo anterior nos dio acceso al proceso de reinserción social, teniendo como antecedentes las violencias ilegítimas, es decir aquellas que las leyes y códigos penales vigentes estipulan como delitos donde se implica el uso de la violencia. Para los fines de este trabajo era necesario que el delito cometido implicara un proceso de reinserción prolongado: de ahí que se escogieron jóvenes que cometieron homicidio, quienes tenían resoluciones judiciales de llevar "tratamientos" de reintegración social de 9 años en promedio.

Ya que no se encontraron mujeres procesadas por este acto, la muestra consta solo de personas del sexo masculino. La edad promedio de los jóvenes fue de 19 años, quienes refirieron haber estado bajo el efecto de distintas sustancias adictivas al momento del delito, uno de ellos declaró solo haber consumido alcohol, los otros tres refirieron combinaciones de metanfetamina, marihuana y otras drogas. Dos de ellos tenían una relación de parentesco con las víctimas, otro de ellos una relación de amistad y otro solo conocía a su víctima por vivir cerca de su domicilio. Los 4 informantes son:

A1. Ingresó al Centro en 2011 por homicidio calificado por traición. Asesinó a un amigo, después de una discusión por el botín de un robo que realizaron. Al momento de las entrevistas tenía 19 años de edad.

B1. Ingresó al Centro en 2011 por homicidio calificado con alevosía. Asesinó a una mujer en complicidad con otros dos jóvenes amigos de él, ayudo a uno de sus amigos a perpetrar el homicidio, pero no fue el autor intelectual. Al momento de las entrevistas tenía 19 años de edad.

C1. Ingresó al Centro en 2011 por el asesinato de su tía. La víctima era vecina del joven. Al momento de las entrevistas tenía 19 años de edad.

D1. Ingresó al Centro en 2010 por el asesinato de su padre y de su novia. Al momento de las entrevistas tenía 20 años de edad.

Debido a la negativa de poder ingresar a las instalaciones del CTA con videograbadoras o dispositivos para grabar audio, se optó por elaborar talleres donde se abordaron distintos temas relacionados con la violencia, la familia, el consumo de drogas, entre otras actividades, con la finalidad de obtener registros de puño y letra de los informantes, a través de dibujos, cuestionarios y relatos escritos sobre la vida antes del delito y dentro del CTA. Fueron siete talleres con duración aproximada de dos horas cada uno. De esta manera se pudo lograr vincular las interacciones sociales antes del delito y dentro del CTA.

Cabe mencionar que el proceso para poder acceder al CTA y a los jóvenes informantes no fue sencillo ni estuvo exento de complicaciones. Se logró el acceso al Centro a través de la gestión de nuestras instituciones de adscripción y como parte de un programa más amplio que incluyó actividades culturales y recreativas además de los talleres antes mencionados.

Los primeros acercamientos con los jóvenes en el CTA fueron en calidad de observadores, pues al inicio de este proceso de investigación no se tuvo el permiso para interactuar con los jóvenes. Como observador, en los recorridos por el lugar, fue posible posicionarse en distintos puntos donde se concentraban grupos pequeños de jóvenes. El espacio denominado "el cuadro" es la parte central del CTA: ahí se encuentran las canchas de futbol y de basquetbol, es un lugar de esparcimiento, pero también un lugar privilegiado para observar el comportamiento de los 
jóvenes. La vigilancia de los custodios es desde el perímetro. Los jóvenes entienden que en esta área son observados, no solo por los custodios, sino también por el personal administrativo de la institución.

"El cuadro" es también un espacio donde los jóvenes pueden liberarse de las actividades programadas. Estar en "el cuadro" no siempre significa ser monitoreado, salvo por los custodios que tienen esta misión. En "el cuadro" pueden hacer deporte o reunirse en grupo a platicar. Durante los primeros tres meses se observaron las distintas áreas de interacción de los jóvenes, principalmente este espacio. Posteriormente se programaron los talleres propuestos en sesiones de dos horas semanales durante siete semanas consecutivas.

La información obtenida a través de los textos escritos por los jóvenes se analizó cualitativamente mediante la herramienta AtlasTi. En ciertas ocasiones los jóvenes mostraron resistencia a expresar abiertamente sus experiencias, debido a la presencia de dos personas adscritas a la institución, fungiendo solo como observadores, de aquí que la observación de las expresiones corporales se registrara en notas y diarios de campo, fortaleciendo las interpretaciones subjetivas de las cotidianeidades de los jóvenes.

\section{Desarrollo}

\subsection{Juventud y adolescencia}

Con el surgimiento del concepto moderno de juventud, en el periodo de la Revolución Industrial, se pensó a los jóvenes a partir de la escuela y el trabajo, y consecuentemente la categoría de juventud se construyó en función de estas instituciones. Incluso antes de la concepción moderna de juventud, la categoría de juventud suele construirse desde una escala etaria, como un proceso lineal (niño,joven, adulto), además paulatino y en constante construcción. De lo juvenil incompleto y subordinado a lo adulto realizado y pleno. Un claro ejemplo, es el trabajo del psicólogo Stanley Hall (1915) quien, en lo albores del siglo XX, no hablaba de jóvenes, sino de adolescentes, reflejo de un individuo envuelto en una época de tempestad y de estímulo. Así mismo desde la antropología de la segunda década del siglo XX, Margaret Mead (1985) plantea la adolescencia como una etapa de conflicto e indecisión y como una reacción a las restricciones de la civilización.

Pérez Islas (2010) plantea como las instituciones, especialmente las de la vida moderna, son las que, al ir distinguiendo los límites de los tiempos y espacios sociales, van construyendo la categoría de juventud. "La producción social de lo que se llama juventud está relacionada con el desarrollo y transformación de tres instituciones sociales: La familia, la escuela y el trabajo” (p. 29).

En estos procesos de transformación de las instituciones sociales expuesto por Pérez Islas (2010), podemos encontrar elementos comunes. Estas transformaciones de la familia, la escuela y el trabajo, aunque han sido paulatinas, parecen responder a una serie de rupturas más o menos violentas e impetuosas. No son, en el mejor de los casos, una transición negociada. Quien lleva la "peor parte del trato" han sido, históricamente los jóvenes. En estas transformaciones, otro elemento en común es la figura de autoridad. Ya sea en la escuela, el trabajo y por supuesto, la familia, hay un constante replanteamiento de la autoridad y sus límites. 
El trabajo y por supuesto, la familia, como instituciones separadas por tiempos y espacios particulares, imponen reglas, códigos y patrones, que muchos de los jóvenes no comparten. Esto genera que la juventud no se identifique con estos proyectos derivados de las transformaciones institucionales.

Al ser marginados, excluidos y muchas veces ignorados en estos proyectos, es común que comiencen a identificarse a través de códigos y prácticas propias. Esto provoca la creación y búsqueda de espacios alternativos, muchos de los cuales se generan al margen de las instituciones antes mencionadas. De esto se da cuenta en varios de los estudios sobre juventudes como los realizados por Reguillo (1995), Valenzuela (1997) y Feixa (1998), por mencionar solo algunos.

Para Bourdieu (1990) la juventud es una construcción social. La sitúa como una frontera social entre la vida adulta y la niñez. Además, lo concibe como un grupo social constituido por una edad e intereses comunes, definido por la clase social. Asimismo, hay que denotar la profundidad y el peso social que conlleva la categoría de juventud, pues no solo la clase social y la ocupación determinan la condición juvenil, pues también se construye a través de las identidades y adscripciones juveniles. La juventud está cargada de significados y prácticas sociales históricamente determinadas por expresiones culturales múltiples, asociados con elementos de su transición a la adultez, por lo que existen distintas maneras de ser joven (Valenzuela, 2009; Nateras Domínguez, 2010).

En este sentido la clase social tiene un papel preponderante en las formas de ser joven, pues las clases medias y altas son objeto de consumo para el mercado global. La prolongación de la etapa juvenil en estas clases sociales coloca a este sector social como principales consumidores de las nuevas tecnologías, de la moda y de casi cualquier producto cultural. Por otro lado, las clases bajas no corren la misma suerte, pues no tienen acceso a ciertos bienes de consumo. Los más empobrecidos son el principal objeto -pero no el único- de marginación y criminalización (Valenzuela, 2009).

En la juventud, un individuo se afirma como ser social, constituye una etapa en la que las estructuras sociales sitian a estos actores, dotándolos de una suerte de disposiciones aparentemente innatas o propias de la edad que los excluyen y marginan de las prácticas sociales relacionadas a la toma de decisiones, autoridad, libertad sexual, entre otras. De ahí que muchas veces en el discurso de las instituciones, como las de reinserción social de los menores infractores, se recurre al término de adolescencia, que contiene ciertas implicaciones relacionadas con el desarrollo biológico, emocional y conductual en una etapa considerada inestable e inacabada del individuo.

En esta etapa, la adaptación social supone dificultades cognitivas y emocionales, pues, más que el cambio de la niñez a la adultez, la adolescencia implica cargar con las normativas y expectativas sociales. Por ellos es que, los jóvenes buscan entender cómo es su entorno social y extraen opiniones sobre los diversos aspectos de la vida, buscando modelos identitarios afines a ellos. En las instituciones mexicanas parece persistir la relación intrínseca entre el concepto de juventud y la edad de los individuos, particularmente al periodo de cambios biológicos asociados a la adolescencia (Pérez y Urteaga, 2004). Esta transición a la adultez no puede reducirse a la maduración sexual, comúnmente acompañada de diversos cambios hormonales asociados con la inestabilidad emocional y la rebeldía ante las reglas y normas sociales. La juventud y por lo tanto la adolescencia, como construcción social, precisa su incorporación a una sociedad cuyos valores institucionalizados suponen la ubicación e intervención social en función del supuesto de una 
madurez física y social. Es decir, en la juventud se reconocen roles específicos y se internalizan los campos semánticos que estructuran interpretaciones y comportamientos en el contexto institucional. De esta manera, también se señala el paso de un estado natural al cultural, así como el despertar del sentido social, de la emotividad y la conciencia (Berger \& Luckmann, 2006; Urteaga, 2011).

Transitar la juventud, y en particular la adolescencia, no resulta fácil pues en nuestra sociedad se le atribuyen distintas conductas de riesgo asociadas a una etapa biológica y psicológica del desarrollo que pueden facilitar la comisión del delito, principalmente en hombres de clase social poco favorecida (Aula, 2011).

\subsection{Interacciones en el encierro}

Un joven que ha cometido un delito y que inicia un proceso de readaptación social, es sometido a un reencauzamiento de su conducta a través de instituciones como lo son las correccionales o prisiones. Goffman (2007) plantea que una prisión, entre otras instituciones, son instituciones totales, pues quienes pertenecen a ellas sea voluntaria o involuntariamente deben realizar actividades programadas como parte de su vida cotidiana, hay una autoridad que se encarga de que esto se lleve a cabo y de no ser así hay consecuencias para quien no las ejecuta. En el caso de una prisión o una correccional, no salir de la celda o dormitorio es una reprimenda. Esto con la intención de mutilar el Yo del sujeto colocando una barrera entre el exterior y el interior en relación con la persona.

Para Foucault (2009) lo anterior constituye un ejercicio de poder sobre el cuerpo: someter, utilizar, trasformar y perfeccionar aquello que se sale de la norma, coaccionándolo hasta convertir aquello que se resiste en un cuerpo dócil. El dominio del cuerpo en las instituciones penales, es un poder que se ejerce como estrategia, no como privilegio, con la finalidad de controlar la existencia del otro. La disciplina fábrica individuos, de tal suerte que los dispositivos de poder ejercidos sobre los jóvenes minimizan no solo cualquier indicio de indisciplina, sino que también, reducen su capacidad de oponerse a las reglas y normas del establecimiento de reinserción social. La relación dicotómica locura-crimen construida por la disciplina jurídica, permea la percepción que tienen ellos mismos sobre su situación o sobre sus actos (Foucault, 2001; 2009).

Goffman (2006) menciona que existen interacciones del actor para resistir disposiciones de poder y dominación. De aquí que aparezcan de manera casi invisible pequeños actos de resistencia u oposición. Al tener que aceptar y obedecer órdenes, se le concede al actor un margen de expresiones reactivas que salvaguardan su Yo. Por ejemplo, gestos de mal humor, maldecir entre dientes, entre otros. Las personas recurren a una representación dramática para interpretar su mundo acorde a la reacción que el otro tiene sobre sus actos, re-significándose como persona y re-configurando su actuación constantemente. De esta manera re-construye su realidad y su Yo social mutilado en el encierro.

George H. Mead (1973) sugirió estudiar la experiencia humana desde el punto de vista de la sociedad, en razón de que un individuo pertenece a una estructura u orden social. Además, consideraba que en las conductas humanas había procesos internos que le daban significado a la experiencia. Por ejemplo, si un individuo tiene sed, la satisface como cualquier otro ser vivo, pero la manera de satisfacerla (beber de un vaso, elegir el tipo de bebida o incluso posponer el tiempo para hacerlo) requería de procesos mentales. Es decir, llevar a cabo una acción humana 
requiere de una fase previa a la acción, lo cual no es una simple compulsión o mandato, sino un acto reflexivo.

El gesto en la propuesta de Mead refiere al acto social que sirve de estímulo para la reacción de otros individuos. La persona busca entender al otro re-significando su Yo social, a través de la percepción que el individuo tiene del exterior así, en el gesto se encuentra un significado creado al interior de una estructura social. Por lo tanto, el gesto conlleva actos significativos que provocan una reacción en otros distinta del significado del gesto original. Estos actos son un ir y venir en la interacción humana con la finalidad de comprender el mundo.

Si bien, un símbolo signifícate (manifestar abiertamente un sentimiento, una idea, etcétera.) funciona mejor si lo analizamos pragmáticamente como un gesto corporal, las dificultades metodológicas nos llevan a profundizar teóricamente en la interacción gestual, ya que, debido a las características institucionales, los jóvenes se abstienen de explicar abiertamente alguna inconformidad. De aquí que la labor de Erving Goffman sobre la interacción cara a cara resulte favorable para sostener el análisis sobre las interacciones al interior del Centro de Tratamiento para Adolescentes (CTA). Goffman (2006) plantea la dramaturgia como propuesta para comprender los significados que las personas les dan a sus interacciones en la vida cotidiana. Esto es una representación (casi) teatral de la persona, teniendo como escenario una fachada. La fachada son aquellos elementos externos a la persona que sirven para llevar a cabo la representación del acto (un médico requiere un consultorio, un bombero un traje y un incendio, etcétera). Estos elementos están dados en una institución total.

Goffman (1970) advierte que mostrar emociones como ira, miedo, felicidad o tristeza en lugares como la prisión puede considerarse signo de debilidad, inferioridad, derrota, culpabilidad, entre otras, por lo que los jóvenes deben intuir qué conductas deben mostrar ante los demás. Esto no significa que sus emociones sean falsas, sino que mostrar y mantener emociones como la ira o el miedo no son de beneficio dentro de la institución. A su vez, Berger y Luckmann (2006) mencionan que tanto el organismo como el Yo social no puede entenderse adecuadamente si se le separa del contexto social del que forman parte. Esto significa que, al separarlo de su contexto social (familia, amigos, etcétera), lo que está en juego es la estabilidad de su Yo social. Ante los demás la vida en prisión no tendría nada de cotidiana, pero después de un periodo de adaptación, el encierro sería para los jóvenes parte de la rutina.

Al ingresar al CTA es indispensable aprender las normas y reglas, así como las pautas de interacción, tanto con el personal adscrito a la institución como con los jóvenes internos. Para los jóvenes internos adaptarse a la vida dentro del CTA lleva tiempo. Los jóvenes de recién ingreso son quienes frecuentemente reciben castigos por su comportamiento, tienden a romper las reglas, por su resistencia ante las normas, por riñas o violencia. Goffman (2007) menciona que una de las primeras rupturas del Yo es el looping, lo que define como una reacción defensiva fallida. La resistencia cede ante las medidas disciplinarias, se doblega el cuerpo y las emociones. Respecto a esto, los jóvenes comentaron: "nosotros ya lo sabemos y no nos metemos en broncas". Estos discursos sugieren que el tiempo dentro del CTA les enseña las pautas de comportamiento, aprenden los momentos para actuar y que ciertas formas de resistencia ante las normas y reglas no les traerán beneficios. 
Lo anterior podría reafirmar la misión institucional de reinserción social, lo que sugiere que los relatos sobre la percepción de sí mismos van encauzados a mostrar "la plena reincorporación familiar, social y cultural de los adolescentes" (Ley de justicia para adolescentes del Estado de Baja California, 2006, p.15). Sin embargo, no sucede lo mismo con la propia realidad de los jóvenes, pues cada uno de ellos tiene su propia manera de ver su infortunio y con ello se forman un concepto de sí mismos. Para matizar sus discursos de cambio, estos jóvenes hablan de un antes y un ahora. Por ejemplo, uno de ellos menciona que antes de entrar al CTA era "flojo, muy grosero, no trabajaba, no estudiaba ni iba a terapia". Otro dice: "era un desmadre, andaba en drogas, alcoholismo, pandillas, robos, no pensaba las cosas, no estudiaba”. Uno más comenta: “era rebelde, drogadicto, peleonero, fiestero, mujeriego". Todos estos adjetivos estigmatizadores reproducen un discurso institucional como prueba de haber llevado una vida fuera de la norma. Palabras que no pertenecen a un lenguaje cotidiano común a los jóvenes de su edad como: "Ingobernable", "alcoholismo", "ni iba a terapia". Sin embargo, al hablar del ahora, un joven comenta "soy un poco pasivo y no tan impulsivo, buena persona, fácil de tratar, amigable, travieso y juguetón, llevado un poco, pero se respetar". Otro menciona: "pues al día de hoy soy amoroso, sincero, simpático, amistoso, trabajador, estudioso, respetuoso, soy deportista”. Uno más comenta "soy amigable, respetuoso, chistoso, a veces enojón" y añade "soy una persona que siempre comete errores pero que hay que aprender de los errores". En contraste con la opinión de su pasado, el presente resulta prometedor, y significa: tranquilidad, amistad, amor, respeto y reconocimiento de los errores cometidos.

Estas afirmaciones no constituyen propiamente como ellos se ven a sí mismos, sino que representa una suerte de discursos institucionalizados o de actos verbales por medio de los cuales evalúan su situación o su posición dentro del CTA. Tanto en sus expresiones verbales como en las no verbales, estos jóvenes buscan ser coherentes con las expectativas que la institución tiene de ellos. Uno de los retos en esta investigación fue tratar de discernir en que medida estos cambios en la conducta y el discurso de los jóvenes responden a estas expectativas de la institución como una estrategia para sobrellevar el encierro. Esto no impide que dichas expectativas se cumplan, pues, en efecto, sus comportamientos fueron respetuosos y pueden ser percibidos como "amigables", “trabajadores" y "estudiosos".

Para estos jóvenes es difícil no meterse en problemas debido a estos cambios en sus dinámicas cotidianas. Por ejemplo, como comentó uno de los jóvenes:

\footnotetext{
...una nueva regla es no decir groserías, pero cuando estás en ‘cuadro' jugando fútbol no puedes evitar decir cosas y por eso te dan 'certificaciones' [llamadas de atención verbales o escritas]: así crecimos diciendo groserías y ahora no se puede, seguido inventan nuevas reglas para castigarnos.
}

Para evitar sanciones, los jóvenes acatan la disciplina institucional. En este sentido, deben realizar distintas actividades que les ayuden a mejorar la percepción que se tiene de ellos, por lo que la escuela, cursos, talleres y psicoterapia son opciones para que se les vea con disposición de cambio y buen comportamiento. El principal beneficio de una "buena conducta" podría ser la reducción del tiempo de condena. En contra parte, negarse a asistir a las actividades programadas por el CTA tiene como consecuencia la prohibición de ver televisión o salir a "el cuadro". 
Sin embargo, a pesar de estar conscientes de que al seguir las reglas obtienen beneficios, en algunas ocasiones, estos jóvenes pierden el control de sus acciones y se niegan a asistir a la escuela, o a los cursos, talleres o actividades que el CTA indica. Esto tiene consecuencias e incluso puede retrasar su avance en el camino a la reinserción social.

Existen dos tipos de espacios en la vida cotidiana de los jóvenes. El primero lo constituyen los espacios visibles, en los cuales los jóvenes desarrollan actividades a la vista tanto del personal adscrito como visitantes. Estos espacios son los salones de clases, la biblioteca, los cubículos de terapia o los talleres, el área médica, el comedor y "el cuadro". En estos espacios es fundamental la disciplina, pues a la menor falta o indicio de resistencia a las actividades los jóvenes son regresados al dormitorio.

Según lo expresado por los propios jóvenes ellos resisten a las provocaciones, tanto de sus compañeros como de los custodios, y que si bien, jamás se presentó algún incidente en el que un custodio violentara a alguno de los jóvenes, si insinuaron ciertos conflictos entre los jóvenes y los custodios. En una ocasión, un joven se acercó a la puerta de la oficina de custodios y pidió un jabón enviado por su madre. Después de unos minutos se le entregó. Algunos internos se acercaron al joven y le pedían un poco, querían olerlo, él respondió con negativa. Entre los internos intentaban arrebatarle el jabón. Uno de sus compañeros le cuestionó - ¿Verdad que antes no te importaba el jabón que usabas? El joven interno cabizbajo murmuró negativamente. Ante el hostigamiento de los demás jóvenes por el jabón, aquel joven solicitó lo dejaran regresar a la celda. Después de este incidente, las actividades continuaron con regularidad. El jabón no es solo un artículo de limpieza con un agradable olor, los sentidos y significados que transportan a este joven a un lugar fuera del internamiento conlleva una serie de recuerdos que son anclajes a una identidad que no se ha perdido. El tratamiento en estas instituciones implica una pérdida del Yo a través de medidas disciplinarias que encauzan sus conductas. Desde el discurso oficial, reeducan y reintegran a la sociedad. Los jóvenes se adscriben a identidades temporales, mientras termina el tratamiento y buscan a través de llamadas telefónicas, objetos del exterior enviados por familiares sujetarse de esa identidad mutilada y dócil.

Los espacios invisibles son aquellos donde los jóvenes son vigilados exclusivamente por personal autorizado. Estos espacios son los lugares de descanso, pero también de castigo y están confinados en grupos: a estos lugares los jóvenes les llaman "celdas", aunque la institución refiere que son los dormitorios. Hay aproximadamente 6 camas por dormitorio y vale la pena señalar que la cama es el único espacio del cual pueden apropiarse. No realizar actividades afuera o ser castigado implica quedarse todo el día en este lugar. Otro de los espacios invisibles es el baño, que, aunque no cuenta con la suficiente privacidad, sí pueden gozar de cierta intimidad, esto significa menor vigilancia, pero no nula, pues siempre hay alguien observándolos. La carencia de privacidad dificulta satisfacer algunas necesidades fisiológicas, por ejemplo, masturbarse. Uno de los jóvenes comentó que él se masturba en su cama por las noches, pero siempre corre el riesgo de ser descubierto por algún compañero o custodio. Para otros, el lugar adecuado para ello es el baño: ese pequeño espacio personal y público a la vez, pues siempre está bajo la mirada oculta de los vigilantes.

Los jóvenes son vistos al interior del CTA de distintas maneras. La función de los custodios es mantener el orden a través de la disciplina, para ello suelen reducirlos a seres inferiores de los que se debe desconfiar. Durante los talleres que se realizaron, los cuatro jóvenes participantes 
se negaron a emitir comentarios con respecto a su relación con los encargados de la vigilancia. Sin embargo, hubo otros espacios y momentos, donde los jóvenes pudieron compartir su sentir y experiencia sobre quienes les vigilan.

Un joven platicó brevemente sobre los "roces" con los custodios: "me irritan [...] por cómo te piden las cosas con prepotencia y con esa forma de querernos hacer ver como que nosotros no somos nadie aquí en este Centro [CTA]". Institucionalmente podría llegar a ser adecuado el rol de los custodios, pues su fin primordial es garantizar el orden. Para los jóvenes es difícil mantener la calma, y solo les quedan las sonrisas disimuladas, los gestos, agachar la mirada, etcétera; discursos de resistencia ante la disciplina del CTA. De aquí que, el no decir, dice más. Esto también es un ejercicio de poder, paradójico tal vez, pues, si bien, los jóvenes no pierden su posición de dominados, resguardan sus cuerpos con el silencio.

En las primeras incursiones en el Centro se tuvo la oportunidad de conversar con algunos de los oficiales, quienes fueron amables y aclararon algunas de dudas con respecto al funcionamiento del lugar. También contaron historias sobre los jóvenes internos y de lo "peligrosos" que pueden llegar a ser. La observación hacia los jóvenes es de alerta constante, principalmente con quienes han cometido homicidios.

Un rol opuesto al de los custodios lo ejerce el personal administrativo del CTA, psicólogos, trabajadores sociales, entre otros, quienes se refieren a los jóvenes como "pobrecitos", "no los quiere su familia”, “él está triste, estos temas lo ponen mal”, etcétera. El personal administrativo se encarga de resaltar las normas de humanidad de la institución (Goffman, 2007, p. 84), aunque muchas veces esta actitud hacia los jóvenes es de carácter paternalista, donde se hacen ciertas concesiones y se les transmite afecto y apoyo como estrategia para motivar a los jóvenes.

En el CTA, las formas de comunicarse al exterior son limitadas y controladas: una breve llamada telefónica, una carta de algún familiar o amigo, o breves accesos a las tecnologías de la información. Con todo, los jóvenes saben que el mundo se mueve a un ritmo distinto del de ellos, y aunque nunca fueron ajenos a la cultura digital, tras insertarse en la sociedad, es muy probable que sus habilidades sociales y tecnológicas estén en desventaja con las de otros. La principal forma de control recae sobre las llamadas telefónicas. Los jóvenes deben cumplir con ciertas pautas de comportamiento para acceder a llamar a un familiar. Lo cual es algo difícil de lograr al final de la semana, pues en ocasiones cometen actos de indisciplina que los privan de una llamada o de salir al cuadro. Cada viernes los jóvenes que se comportaron bien tienen permiso para recibir llamadas de familiares, aunque hay otros que no reciben llamadas: no por indisciplina, sino porque sus familiares no los llaman ni los visitan. Esto en relación al delito cometido y porque la convivencia de las familias se torna conflictiva por las limitantes que la prisión les impone (Cerda, 2014). De aquí que el personal administrativo en ocasiones o con ciertos jóvenes en lo particular, jueguen un rol de empatía y comprensión. Pero no siempre es así, además la misma institución impone sus estrategias que despersonalizan al joven y no permiten generar esa empatía con el interno.

Goffman (2007) plantea que las primeras estrategias de las instituciones totales es mutilar el Yo del interno. Un ejemplo de esto podríamos observarlo en la vestimenta (pantalón y sudadera deportiva color gris, camisa blanca debajo) y el corte de pelo al ras por igual en todos los internos, lo cual constituye una homogenización de las características individuales. De esta manera el interno es despersonalizado, reducido a perder -aparentemente- su identidad. La disciplina comienza ahí con este acto. 
Los jóvenes llegaron con ciertas marcas o tatuajes, que los definen individualmente. Un común denominador en los tatuajes de estos jóvenes son sus apellidos, el nombre o la insignia del barrio al que pertenecen. También mencionaron portar varias cicatrices en distintas partes del rostro y cuerpo, todas ellas producto de peleas callejeras. Según la institución reformadora, estas marcas y tatuajes ya no deberían definirlos, por lo que el proceso homogeneizante institucional trata de ocultarlos con la vestimenta similar para todos. Como una estrategia de resistencia a la institución y de revalorización de la individualidad, algunos de ellos optaron por resignificar su cuerpo con nuevas marcas y tatuajes hechos durante su estancia en el Centro, "al bravazo", con lo que tienen a la mano dentro del CTA. Se les distinguen algunos tatuajes de trazos simples, muchas veces realizados con las mínimas normas de higiene.

En el encierro, rasgarse el cuerpo es una falta de disciplina, por lo que quien emprende un ataque a su propio cuerpo (rasgaduras, cortes, firmas) es objeto de castigo. Las relaciones de poder y dominación implican el control sobre el cuerpo, y permitir que los jóvenes tomen dicho control significa la pérdida de poder de la institución reformadora.

Originalmente se trabajó con cinco jóvenes, pero en las primeras sesiones un incidente provocó el traslado de uno de ellos a otro Centro. El joven B1 sufrió un episodio de ansiedad por no recibir la llamada de su madre. El joven decidió rasgarse los brazos con un objeto de plástico duro, haciéndose heridas profundas en la piel. Este evento de automutilación no fue el primero de este joven, por lo que los castigos acostumbrados para este tipo de actos no fueron suficientes y se requirieron medidas disciplinarias más severas, pero a su vez, humanitarias pues el lugar al que fue trasladado facilitaba las visitas de los familiares de este joven.

También la familia es una manera de anclarse con el exterior y es a través de las emociones que se conectan con la vida exterior. Para los jóvenes la familia "lo es todo", son las personas que quieren, que le dan felicidad a su vida, las que están con ellos en las buenas y en las malas a pesar de sus errores. De ahí que lo jóvenes expresen discursos que denotan un apoyo incondicional familiar, o bien, pensamientos fatalistas o de baja autoestima cuando no cuentan con la compresión o el apoyo de sus familias: con todo, el abandono no les impide aferrarse a la idea de reconciliarse con sus familiares.

Los jóvenes son conscientes de su realidad y del estigma que cargan, lo que ellos llaman “etiquetas". D1 mencionó: “aunque en el expediente nos queda el delito (homicidio calificado) como infracción, la gente que sabe lo que hicimos, no nos acepta". La lucha no solo es por sobrevivir al encierro y todas sus vicisitudes, también deben convencerse a sí mismos que podrán seguir adelante y que no todo el tiempo vivido en ese lugar ha sido en vano, mal gastado o perdido. B1 comentó lo siguiente:

La verdad yo estoy seguro que ya cambié, aunque los demás piensen que soy agresivo o que me castigo mucho. Pero están equivocados porque yo si quiero cambiar, porque si no quisiera cambiar no estaría en tantas actividades y si en verdad solo quisiera desperdiciar mi tiempo, solo no asistiría a ninguna actividad, más que al "cuadro" pero de lo contrario hago todo lo posible por aprender cosas buenas. 
Por su parte, C1 relata:

Mis amigos me ven bien, no me dejaron de hablar por este caso y las demás personas me dicen que a pesar de que cometí un error muy grande dicen que soy buena persona, buen estudiante y eso me hace sentir bien. Y pues [con] mi familia no tengo contacto, pero mi hermano me dice que no hay pedo, que todo está bien.

En este sentido, estos jóvenes ya no son aquellos jóvenes violentos que desobedecían a sus padres, que retaban a la autoridad, sino jóvenes coaccionados como personas obedientes, evitando a toda costa mostrar algún rasgo violento. Por lo tanto, existe una diferencia entre el joven en un contexto de libertad y el que está dentro del CTA. Algunos de ellos comentan que con el tiempo "agarran la onda" y que se dan cuenta cómo deben actuar para evitar problemas con las autoridades dentro de la institución. Los jóvenes construyen entonces máscaras bien elaboradas sobre sí mismos que adaptan perfectamente a su contexto actual. La máscara -según Goffman (2006)- no necesariamente es un acto consciente, es posible que los jóvenes tengan tan interiorizada su actuación que no se percata de su existencia. Estos jóvenes se aferran a los vínculos afectivos familiares por ser el referente que los mantiene ligados al exterior, al Yo social que protegen con su máscara.

Los jóvenes se expresan con cariño y amor por sus familiares, y evitan externar situaciones que involucren acontecimientos familiares que pongan en evidencia sentimientos de rencor o molestia. Si bien estos afectos son una forma de anclarse con el exterior, resulta también una actitud conveniente, ya que en sus interacciones con el personal del lugar encuentran una confirmación o desacreditación en su actuación a partir de las reacciones. Esto significa que hablar de sus afectos familiares da cuenta de cambios positivos para los encargados de su reeducación.

Uno de los jóvenes mencionó lo siguiente en uno de los talleres:

Con mis abuelos me llevaba bien, eran bien chilos conmigo, ellos siempre quisieron lo mejor para mí y con mis hermanos siempre los he querido mucho y era buena relación con ellos, hasta hoy no tengo contacto con ellos, pero eso no me impide que los quiera como los quiero.

La pérdida de contacto con sus hermanos a raíz del acto violento que lo llevó al Centro refuerza la necesidad de anclarse a aquellos afectos que él considera verdaderos. Los vínculos afectivos hacia sus hermanos alimentan sus ganas de salir adelante en el futuro: “y eso me hace más fuerte para pensar mejor las cosas y prepararme en todos los sentidos y poder salir trabajando, estudiando y no usar drogas".

Goffman (2007) menciona que la habituación a las normas institucionales les dificulta adaptarse nuevamente a la vida social en libertad. En el camino a la reinserción social, estos jóvenes cargan un estigma que no disminuye y conforme se acerca el fin del tratamiento, más crece la incertidumbre de volver al exterior. Esto puede llegar a ser desmotivante, pues el tiempo en internamiento los confinó a cierto espacio en donde las reglas son diferentes a las del exterior, lo cual implica un trabajo de readaptación a la vida en libertad. 
Podría considerarse que el tiempo que viven los jóvenes internos transcurre a otro ritmo, un ritmo mucho más pausado. La relatividad del tiempo social cobra sentido al constatar que el estadio juvenil se prolonga en estos sitios más de lo ya prolongado en otros espacios juveniles (Valenzuela, 2009). Las vivencias de los jóvenes internos son distintas a las de jóvenes en otras circunstancias más favorables. Ellos siguen siendo aquellos "menores infractores" que ingresaron al CTA, aun cuando ya cruzan el umbral de los veinte años de edad.

\section{Conclusiones}

En situaciones extremas, como el encierro, el cuerpo experimenta una existencia dual, una lucha por la supervivencia diaria y una lucha contra el propio cuerpo por aguantar incomodidades, la disciplina, la falta de intimidad, etc. En situación de reclusión, lo que queda es el cuerpo, al cual, hay que darle significado. Hay que diferenciarlo de los demás cuerpos para no correr el riesgo de desaparecer. Cuando el silencio llega, el cuerpo es el lienzo donde el joven escribe y dibuja su historia, en donde se inscribe lo que ve y lo que escucha.

Una manera de contrarrestar la disciplina de la institución la hallamos en la manera de resistir o desafiar los dispositivos disciplinarios que deciden sobre el propio cuerpo, por ejemplo, a través de los tatuajes, los cortes de piel, etc., (Valenzuela, 2009). Al interno lo único que le pertenece y en donde puede apoyarse es su cuerpo, y este se vuelve un dispositivo para mostrar su individualidad bajo estas circunstancias. Por esto es que se vuelve necesario para los jóvenes reescribir su ser (Yo) bajo sus propios términos, es necesario construirse una nueva apariencia, un cuerpo propio.

Para estos jóvenes, conforme pasó el tiempo fue cambiando su actitud, aprendieron las formas de sobrellevar la vida dentro del CTA. Una de estas formas es el silencio. Durante las sesiones del trabajo de campo en el Centro predominaron los silencios de los jóvenes, los vacíos y contradicciones en sus narrativas. Estos silencios y vacíos esconden en mayor o menor medida emociones, afectos y conflictos. También funcionan a manera de actos performativos para disimular o minimizar el sentido del delito. Muchos de los informantes no quisieron hablar con detalle los actos violentos que los llevaron al Centro, algunos de ellos se limitaron a decir que "fue su peor error”, que en algún momento sintió culpa, pero actualmente se perdonó por lo sucedido y le da tristeza recordar. Quienes describen el acto violento realizado, omiten muchos elementos en la narración, mencionan situaciones como "yo andaba bien loco [y] cometí el homicidio" o “andábamos ebrios" y recurren a pausas prolongadas.

El silencio también es una respuesta ante los cuestionamientos de los custodios y del personal administrativo, es una herramienta para evitar el conflicto. Sin embargo, también los lleva a evitar verbalizar y hacer evidentes sus emociones, sentimientos y sobre todo frustraciones. Esto pudiera implicar una incapacidad temporal para encarar algunos aspectos de la vida en el exterior (Goffman, 2007), lo que equivale a una posible pérdida o disminución de habilidades de socialización al momento de salir.

Durante las interacciones en el trabajo de campo y en las interacciones con el personal del Centro, los jóvenes proyectan un Yo social aceptable, un Yo que confirma las expectativas institucionales evitando reacciones emocionales desmedidas y que les proporciona una significación adecuada (Goffman, 1970; 2006). No es que los jóvenes finjan afectos hacia la familia, sino que evitan 
demostrar abiertamente emociones como ira, miedo, rencor, odio, etc., ya que es necesario exponer solo aspectos personales que beneficien el proceso institucional de reinserción social. La máscara (Goffman, 2006) es una alternativa viable para este proceso.

Este aparente o momentáneo triunfo institucional, obedece más a la manera en que estos jóvenes toman consciencia de sí como actores que, a los discursos institucionales de cambio difundidos en terapias psicológicas, cursos, talleres, entre otras actividades que suponen el encausamiento institucional de estos jóvenes, a los cuales asisten por conveniencia u obligación. La institución modeló las expectativas de una posible reinserción social exitosa. Los relatos de estos jóvenes van encaminados a discursos institucionalizados. Por ejemplo, "poner en práctica lo que han aprendido en el Centro", "demostrar que les ha servido", "no ser como antes", "mantenerse al margen", "trabajar, estudiar, portarse bien, comportarse adecuadamente". Estas palabras se repiten en el discurso de los jóvenes, pues quien no lo dice, no ha cambiado. Por el contrario, tienen miedo a que esto no suceda: el trabajo, la escuela, la familia ¿serán meras fantasías? Ellos se reservan la esperanza de un futuro alentador.

\section{REFERENCIAS}

Acero, Á. R., Escobar-Córdoba, F., \& Castellanos Castañena, G. (2007). Factores de riesgo para violencia y homicidio juvenil. Revista Colombiana de Psiquiatría, 36(1), 78-97. http://www.scielo.org.co/pdf/rcp/ v36n1/v36n1a07.pdf

Aula, Y. (2011). Adolescencia y drogas. Salus, 15(2), 7. http://servicio.bc.uc.edu.ve/fcs/vol15n2/topicos.pdf

Bailón, F. (2012). La escuela correccional de artes y oficios de Oaxaca, 1889-1901. Estudios de Historia Moderna y Contemporanéa de México, (44), 137-173. https://doi.org/10.22201/iih.24485004e.2012.44.35786

Berger, P. L., \& Luckmann, T. (2006). La construcción social de la realidad. Amorrortu.

Bourdieu, P. (1990). Sociología y cultura. Grijalbo.

Cerda, P. (2014). Prisión y familia: retos de la cohesión social en el siglo XXI. Universidad Autónoma de Nuevo León.

Congreso del Estado de Baja California. (27 de octubre de 2006) Ley de justicia para adolescentes del Estado de Baja California. Periódico oficial No.45. http://transparencia.pjbc.gob.mx/documentos/pdfs/leyes/ LeyJusticiaAdolescentes.pdf

Connell, R. W. (2003). Adolescencia en la construcción de masculinidades contemporáneas. En J. Olavarría, Varones adolescentes: género, identidades y sexualidades en America Latina (pp. 53-67). CLACSO.

Feixa, C. (1998). De jóvenes, bandas y tribus. Ariel.

Foucault, M. (2001). Los anormales. FCE.

Foucault, M. (2009). Vigilar y castigar. Siglo XXI.

Goffman, E. (1970). Ritual de interacción. Tiempo Contemporáneo.

Goffman, E. (2006). La presentación de la persona en la vida cotidiana. Amorrortu.

Goffman, E. (2007). Internados. Ensayos sobre la situación social de los enfermos mentales. Amorrortu.

Goffman, E. (2010). Estigma. Amorrortu.

Hall, S. G. (1915). Adolescence: Its Psychology and its relations to Psysiology, Sociology, Sex, Crime, Religion and Education. Appleton Century Crofts. 
Mead, M. (1985). Adolescencia, sexo y cultura en Samoa. Planeta.

Mead, G. H. (1973). Espíritu, persona y sociedad. Paidós.

Medina-Mora, M., Villatoro Velázquez, J., Fleiz Bautista, C., Téllez Rojo, M., Mendoza Alvarado, L., Romero Martínez, M. (2012). Encuesta Nacional de Adicciones 2011: Reporte de Alcohol. INPRFM.

Nateras, A. (2010). Adscripciones identitarias juveniles: tiempo y espacio social. El Cotidiano, 25(163), 17-23. https://www.redalyc.org/pdf/325/32515913003.pdf

Núñez, L. M. (2005). Género y conducta infractora: las y los menores infractores en Hermosillo, Sonora, México. Estudios Sociales, 13(26), 86-115. https://www.redalyc.org/articulo.oa?id=41702604

Pérez Islas, J. A., y Urteaga, M. (Coord.) (2004). Historias de los jóvenes en México. Su presencia en el siglo XX. Instituto Mexicano de la Juventud.

Pérez Islas, J.A. (2010) Las cuatro grandes transformaciones históricas de la condición juvenil. En M. Urteaga. (Coord.) Juventudes, Culturas, identidades y tribus juveniles, Suplemento 23. INAH.

Reguillo, R. (1995). En la calle otra vez. Las bandas: Identidad urbana y usos de la comunicación. ITESO.

SISVEA. (2013). Sistema de Vigilancia Epistemológica de las Adicciones. Informe 2011. Secretaria de Salud, Subdirección de Prevención y Promoción de la Salud, Dirección General de Epidemiología.

SSPE. (2018). Secretaría Seguridad Pública del Estado de Baja California. SSPE

Urteaga, M. (2011). La construcción juvenil de la realidad. Jóvenes mexicanos contemporáneos. Universidad Autonoma Metropolitana.

Valenzuela, J. M. (1997). Vida de barro duro. Cultura popular juvenil y graffiti. Universidad de Guadalajara.

Valenzuela, J. M. (2009). El Futuro ya fue. El Colegio de la frontera Norte.

Vilariño, M., Amado, B. G., \& Alves, C. (2013). Menores infractores: un estudio de campo de los factores de riesgo. Anuario de Psicología Jurídica 2013, 39-45. http://dx.doi.org/10.5093/aj2013a7

Villatoro-Velázquez, J. A., Oliva Robles, N., Fregoso Ito, D., Bustos Gamiño, M., Mujica Salazar, A., Martín del Campo Sánchez, R., Nanni Alvarado, R., y Medina-Mora M. E. (2015). Encuesta Nacional de Consumo de Drogas en Estudiantes 2014: Reporte de Drogas. INPRFM.

\section{Autores}

Christian Fernández Huerta. Doctor en Estudios del Desarrollo Global por la Universidad Autónoma de Baja California. Maestro en Estudios Socioculturales y licenciado en Ciencias de la Comunicación por la misma institución. Adscrito al Instituto de Investigaciones Culturales-Museo de la Universidad Autónoma de Baja California. Sus líneas de investigación son: Juventudes, espacio público, culturas digitales.

Anuar Figueroa Estrada. Licenciado en Psicología y Maestro en Estudios Socioculturales por la Universidad Autónoma de Baja California. Adscrito al Instituto de Psiquiatría del Estado de Baja California. Sus líneas de investigación son: Jóvenes en reclusión y violencia institucional. 